\title{
Influence of vegetation parameters on runoff and sediment characteristics in patterned Artemisia capillaris plots
}

\author{
GuanHua ZHANG ${ }^{1,2,3}$, GuoBin LIU $^{2,3^{*}}$, PingCang ZHANG ${ }^{1}$, Liang $\mathrm{YI}^{4}$ \\ ${ }^{1}$ Department of Soil and Water Conservation, Changjiang River Scientific Research Institute, Wuhan 430010, China; \\ ${ }^{2}$ State Key Laboratory of Soil Erosion and Dryland Farming on the Loess Plateau, Institute of Soil and Water Conservation, \\ Chinese Academy of Sciences and Ministry of Water Resources, Yangling 712100, China; \\ ${ }^{3}$ Institute of Soil and Water Conservation, Northwest A\&F University, Yangling 712100, China; \\ ${ }^{4}$ Hubei Academy of Environmental Sciences, Wuhan 430072, China
}

\begin{abstract}
Vegetation patterns are important in the regulation of earth surface hydrological processes in arid and semi-arid areas. Laboratory-simulated rainfall experiments were used at the State Key Laboratory of Soil Erosion and Dryland Farming on the Loess Plateau, Yangling, northwestern China, to quantify the effects of Artemisia capillaris patterns on runoff and soil loss. The quantitative relationships between runoff/sediment yield and vegetation parameters were also thoroughly analyzed using the path analysis method for identifying the reduction mechanism of vegetation on soil erosion. A simulated rainfall intensity of $90 \mathrm{~mm} / \mathrm{h}$ was applied on a control plot without vegetation $\left(\mathrm{C}_{0}\right)$ and on the other three different vegetation distribution patterns: a checkerboard pattern (CP), a banded pattern perpendicular to the slope direction (BP), and a single long strip parallel to the slope direction (LP). Each patterned plot received two sets of experiments, i.e. intact plants and roots only, respectively. All treatments had three replicates. The results showed that all the three other different patterns (CP, BP and LP) of $A$. capillaris could effectively reduce the runoff and sediment yield. Compared with $\mathrm{C}_{0}$, the other three intact plant plots had a $12 \%-25 \%$ less runoff and $58 \%-92 \%$ less sediment. Roots contributed more to sediment reduction ( $46 \%-70 \%)$, whereas shoots contributed more to runoff reduction (57\%-81\%). BP and CP exhibited preferable controlling effects on soil erosion compared with LP. Path analysis indicated that root length density and plant number were key parameters influencing runoff rate, while root surface area density and root weight density were central indicators affecting sediment rate. The results indicated that an appropriate increase of sowing density has practical significance in conserving soil and water.
\end{abstract}

Keywords: arid and semi-arid areas; Artemisia capillaris patches; runoff and sediment; roots and shoots; vegetation parameters

Citation: GuanHua ZHANG, GuoBin LIU, PingCang ZHANG, Liang YI. 2014. Influence of vegetation parameters on runoff and sediment characteristics in patterned Artemisia capillaris plots. Journal of Arid Land, 6(3): 352-360. doi: 10.1007/s40333-013-0224-5

Arid and semi-arid zones cover approximately $40 \%$ of the earth's land surface, and continuously increase in area due to intensified anthropogenic activities and/or climatic changes (Bernstein, 2008). Climatically, arid and semi-arid areas are characterized by extreme temperature conditions (D'Odorico and Porporato, 2006) and torrential precipitation events of short duration and high intensity (Wei et al., 2007), which lead to low infiltration and consequently, huge amounts of runoff
(Rango et al., 2006). These regions are thus considered fragile ecosystems where vegetation covers are low and soils are susceptible to erosion or desertification (Vásquez-Méndez et al., 2010, 2011).

Vegetation (canopy, understory, and plant roots) is of great importance in regulating surface hydrological processes because they can mitigate the erosion forces of rainfall (Wei et al., 2007; Vásquez-Méndez et al., 2010). Influences of patched patterns of vegetation on

*Corresponding author: GuoBin LIU (E-mail: gbliu@ms.iswc.ac.cn)

Received 2013-05-07; revised 2013-07-15; accepted 2013-08-21

(C) Xinjiang Institute of Ecology and Geography, Chinese Academy of Sciences, Science Press and Springer-Verlag Berlin Heidelberg 2014 
soil erosion have been reported in Africa and Australia since the 1950s (Greenwood, 1957; Worrall, 1959; Beard, 1967). The typical characteristics of vegetation patterns in arid and semi-arid ecosystems are higher plant-cover patches mainly distributed in spots or bands as a mosaic (Aguiar and Sala, 1999). Under some circumstances, plant species in arid and semi-arid regions also displayed several different root distribution patterns (Fowler, 1986; Nobel, 1990). Root zones of perennials are wider and deeper than those of annuals, and phreatophytes are also often very deep-rooted (Vásquez-Méndez et al., 2011). The more recent researches on vegetation patterns have further placed additional focus on the dynamics of the hydrological and erosional processes that generate and sustain this patchiness (Cerdà, 1997; Boer and Puigdefábregas, 2005; Puigdefábregas, 2005). The main idea is that vegetation patches divide the slope into runoff and runon zones, and consequently into erosion (bare) and deposition (vegetated) zones that act as source and sink, respectively (Puigdefábregas, 2005). Dekker et al. (2007) reported that vegetation distribution is generally controlled by precipitation; meanwhile, precipitation distribution affects vegetation development and distribution, which in turn modifies the atmospheric energy and water storage. Bedford and Small (2008) found that spatial patterns of soil properties are generally assumed to be linked to patchy dryland vegetation.

The Loess Plateau of China is characterized by deep loess deposits, a unique landscape of criss-crossing ravines and gullies, and severe soil erosion (Shi and Shao, 2000). The arid and semi-arid lands in the Loess Plateau occupy about $67 \%$ of the entire region ( $\mathrm{Li}$ et al., 2003). The intense soil erosion and frequent anthropogenic activities have caused the extreme degradation of both zonal vegetation and soil quality in this region (Tang, 2004). Therefore, large-scale revegetation has been carried out for the sake of preventing soil erosion and restoring degraded ecosystems (Chen et al., 2008). Over the last several decades, researches concerning the performance of vegetation for erosion control have been widely conducted (Braud et al., 2001; Pan and Shangguan, 2006), and both the above-ground biomass or plant canopy (Pan et al., 2006; Zhou and Shangguan, 2007) and below-ground biomass (Mamo and Bubenzer, 2001a, b; Gyssels and Poesen, 2003; De Baets et al., 2006) have been well studied and documented. However, the information remains rather descriptive. Although the effect of patterned vegetation on erosion control has been recognized in many parts of the world's drylands (Cerdà, 1997) and the above-mentioned ideas are also well known and accepted as a valid theory by most researchers, there is a lack of information or direct experimental data in the ecologically fragile Loess Plateau. Moreover, in most previous studies highlighting the positive effect of vegetation on soil and water conservation, this protective effect has often been related to vegetation cover without taking into account specific vegetation parameters or plant traits, thus the mechanism of vegetation on erosion control might not yet be fully elucidated.

Therefore, the objectives of this study are: (1) to evaluate the effects of patchy Artemisia capillaris on runoff and sediment yield, and understand the relative contribution of plant shoots and roots in reducing soil erosion; and (2) to systemically analyze the quantitative relations between runoff/sediment yield and vegetation parameters (both above-ground and below-ground characteristic parameters) based on path analysis. The findings can offer useful insights into the mechanism of vegetation on erosion control, and provide scientific guidance for suitable land uses and the construction of soil and water conservation measures.

\section{Materials and Methods}

\subsection{Simulated rainfall}

The experiments were conducted under the laboratory-simulated rainfall conditions at the State Key Laboratory of Soil Erosion and Dryland Farming on the Loess Plateau, Yangling, northwestern China. A side-sprinkle set-up was used in the experiments. Simulated rainfall height was $16 \mathrm{~m}$, and the simulated rainfall used, with a uniformity of $>85 \%$, is similar to the natural rainfall. Rainfall intensities can be precisely adjusted through nozzle sizes and water pressure. Calibration of rainfall intensities was performed before each rainfall test.

\subsection{Plot characteristics and experimental treat- ments}

Runoff plots were manufactured with steel boxes, with a dimension of $2.0 \mathrm{~m} \times 1.0 \mathrm{~m} \times 0.5 \mathrm{~m}$. Usually, the slope 
of runoff plots can be adjusted between $0-25^{\circ}$; in this study, we set the slope at $15^{\circ}$, which is a general slope for returning farmland to forestland or grassland on the Loess Plateau. The soil tested was silt loam (US soil taxonomy) and collected from the top soil depth of $20 \mathrm{~cm}$ in an experimental field at Ansai county, Shaanxi province, northwestern China. Its sand, silt, and clay contents were $46 \%, 46 \%$ and $8 \%$, respectively. The soil was air-dried, gently crushed, and then passed through a $10-\mathrm{mm}$ sieve to remove gravel as well as animal and plant residues. Before packing, a $10-\mathrm{cm}$ layer of fine sand was put at the bottom of each plot for better drainage. Then a $30-\mathrm{cm}$-thick soil was packed in three 10-cm layers at a bulk density of 1.2 $\mathrm{g} / \mathrm{cm}^{3}$ in each plot. Each soil layer was raked lightly before the next layer was packed to diminish the discontinuity between the two layers. A. capillaris, a commonly indigenous plant on the Loess Plateau, was taken as the target species. The grass seeds were sown in April 2009 with a row spacing of 10-cm parallel to the plot surface, and similar sowing density was adopted to ensure uniform grass cover for all plots. After sowing, the plots were covered with straw mats and watered to guarantee germination and seedling growth.

Some studies have stated that the threshold cover for vegetation influencing soil erosion is about $50 \%$ (Guo, 2000). The experimental treatments in this present study, designing the same vegetation cover $(50 \%)$ but different distribution patterns, included a control plot
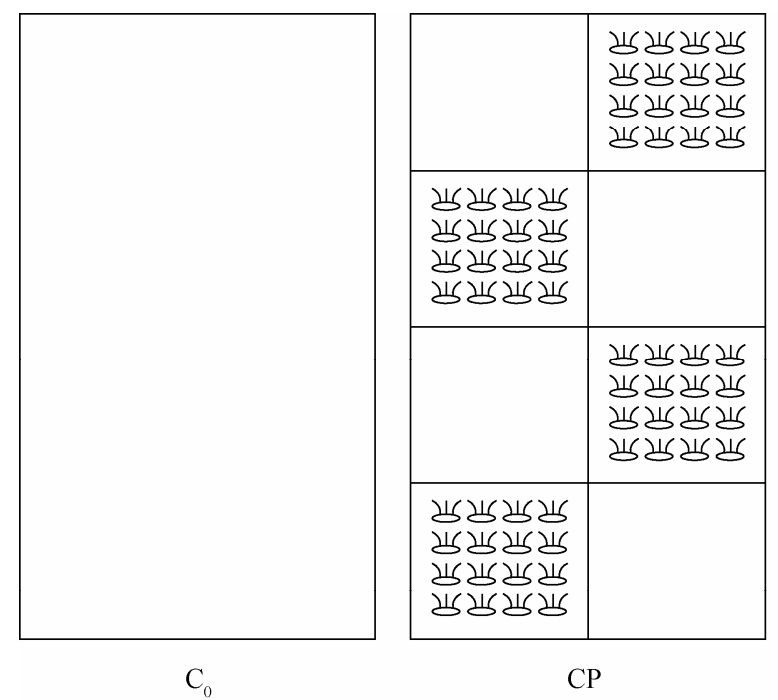

without vegetation $\left(\mathrm{C}_{0}\right)$, a checkerboard pattern $(\mathrm{CP})$, a banded pattern perpendicular to the slope direction (BP), and a single long strip parallel to the slope direction (LP) (Fig. 1). All treatments had three replicates.

\subsection{Measurements of runoff and sediment}

Rainfall simulations were carried out in September 2010 , one year after the target plants had been sown in the soil. In this study, a simulated rainfall intensity of $90 \mathrm{~mm} / \mathrm{h}$ was applied to the plots for $60 \mathrm{~min}$ after runoff initiation. Plastic buckets at the plot outlet were used to collect all runoff and sediment at 3-min intervals during each simulated rainfall event. After the simulated rainfall finished, runoff in each bucket was weighed on a balance. The buckets were then laid aside to stand until the suspended sediment settled out. Then the supernatant was discarded, and the remaining wet sediment was transferred to iron basins to determine the sediment weight after oven-drying at $105^{\circ} \mathrm{C}$ to constant weight. The dry sediment weight was then used to calculate sediment concentration and sediment rate.

After the experiments with the intact plants were completed, the test patches of A. capillaris were clipped at the soil surface, leaving only the roots. All plots were exposed to the corresponding run tests again to investigate root effect on the studied response variables. We referred to the plots with intact plants and with only the roots as 'plant plot' and 'root plot', respectively.

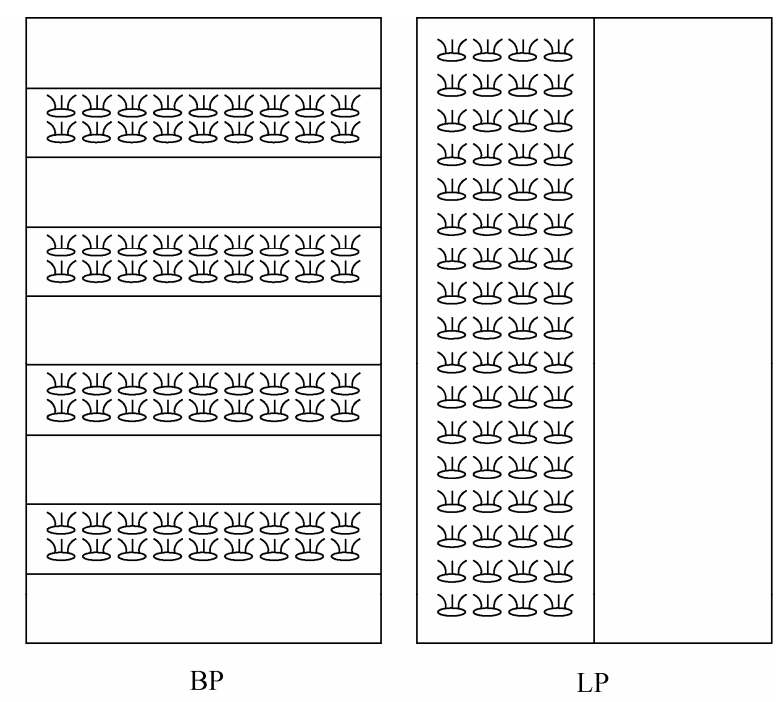

Fig. 1 Experimental plots for different vegetation patterns. $\mathrm{C}_{0}$, control plot without vegetation; $\mathrm{CP}$, checkerboard pattern; BP, banded pattern perpendicular to the slope direction; LP, single long strip parallel to the slope direction. 


\subsection{Measurements of vegetation parameters}

Vegetation parameters were measured again at the end of August 2010, for additional data regarding the actual conditions of the vegetation during the experiments. Vegetation cover was measured using vertical photographs taken with a high-resolution digital camera and empirical estimation by visual inspection. The total stem number ( $\mathrm{SN}$ ) of $A$. capillaris in each plot was counted based on plant clusters, and the stem height $(\mathrm{SH})$ was measured using a tape to further perform the descriptive statistics. The above-ground parts (shoots) of $A$. capillaries were cut off, and these clippings were packed into kraft bags to be measured to determine the above-ground biomass after oven-drying at $85^{\circ} \mathrm{C}$ to constant weight.

When the simulated rainfall experiments finished, eight soil samples were randomly taken in the depth of $0-10 \mathrm{~cm}$ on the root plots with a soil auger $(2.5 \mathrm{~cm}$ in diameter). The roots were separated from the soil samples by washing and dried with filter papers, and then spread on a rectangular transparent plastic sheet one by one. Precautions were taken to avoid root overlapping and abutting so as to minimize error. The roots on the plastic sheet were scanned at a resolution of 300 dpi for their images (Epson Perfection 4490 Photo Scanner, China). Professional analysis software for root morphological and structural characteristics-WinRhizoTron MF 2007b (Regent Instruments Inc., Canada) was used to calculate root length, diameter, area, volume, and root tip number. Scanned roots were transferred to paper bags and oven dried $\left(60^{\circ} \mathrm{C}\right)$ to determine the dry weight.

Generally, the root indicators were defined as follows. Root weight density (RWD) was root mass per unit volume of soil $\left(\mathrm{kg} / \mathrm{m}^{3}\right)$. Root length density (RLD) was total root length per unit volume of soil $\left(\mathrm{km} / \mathrm{m}^{3}\right)$. Root surface area density (RSAD) and root area ratio (RAR) were also used as root parameters. RSAD was total surface area per unit volume of soil $\left(\mathrm{m}^{2} / \mathrm{m}^{3}\right)$, and RAR was the fraction of the soil cross-sectional area occupied by roots (De Baets et al., 2006). Neither of these was measured in this study, but root length per unit volume was converted into equivalent RSAD and RAR using the mean root diameter values, assuming that a root has a circular cross-section. RSAD and RAR were then derived from multiplying RLD by mean root perimeter and cross-sectional area, respectively. These two indicators provide root longitudinal and cross section information for a given topsoil. Statistic descriptions of vegetation parameters for the patterned plots in this study are listed in Table 1.

\subsection{Data analyses}

In the present study, it was presumed that the reductions in runoff and sediment yield caused by intact plants were only the combined effect of shoots and roots. The effects of intact plants and roots on runoff and sediment reductions were calculated from the following equations:

$$
\begin{gathered}
R R_{p}=\frac{R_{c k}-R_{p}}{R_{c k}} \times 100 \%, \\
R R_{r}=\frac{R_{c k}-R_{r}}{R_{c k}} \times 100 \%, \\
R S_{p}=\frac{S_{c k}-S_{p}}{S_{c k}} \times 100 \%, \\
R S_{r}=\frac{S_{c k}-S_{r}}{S_{c k}} \times 100 \% .
\end{gathered}
$$

Where $R R_{p}$ and $R R_{r}$ are runoff reductions that resulted from the intact plants and roots, respectively (\%); $R_{c k}$, $R_{p}$, and $R_{r}$ are the runoff rate in bare soil plots, plant plots, and root plots, respectively ( $\mathrm{mm} / \mathrm{min}) ; R S_{p}$ and $R S_{r}$ are sediment reductions that resulted from the intact plants and roots, respectively (\%); $S_{c k}, S_{p}$, and $S_{r}$ are the sediment rate in bare soil plots, plant plots, and root plots, respectively $\left(\mathrm{g} /\left(\mathrm{m}^{2} \cdot \mathrm{min}\right)\right)$.

Table 1 Statistic description of vegetation parameters

\begin{tabular}{ccccccccc}
\hline Item & $\mathrm{SH}(\mathrm{cm})$ & $\mathrm{SN}$ & $\mathrm{SD}\left(\mathrm{kg} / \mathrm{m}^{2}\right)$ & $\mathrm{RWD}\left(\mathrm{kg} / \mathrm{m}^{3}\right)$ & Dia. $(\mathrm{mm})$ & $\mathrm{RSAD}\left(\mathrm{m}^{2} / \mathrm{m}^{3}\right)$ & $\mathrm{RLD}\left(\mathrm{km} / \mathrm{m}^{3}\right)$ & $\mathrm{RAR}\left(\times 10^{-3}\right)$ \\
\hline Minimum & 52.400 & 60 & 0.194 & 0.083 & 0.384 & 8.978 & 5.813 \\
Maximum & 113.500 & 155 & 0.372 & 0.377 & 0.498 & 31.038 & 21.868 \\
Mean & 81.500 & 99 & 0.272 & 0.196 & 0.450 & 18.297 & 3.360 \\
STD & 10.235 & 32.887 & 0.053 & 0.097 & 0.031 & 6.635 & 0.839 \\
CV & 0.126 & 0.332 & 0.196 & 0.495 & 0.068 & 0.363 & 0.789 \\
\hline
\end{tabular}

Note: SH, stem height; SN, stem number; SD, shoot density; RWD, root weight density; Dia., mean root diameter; RSAD, root surface area density; RLD, root length density; RAR, root area ratio; STD, standard deviation; $\mathrm{CV}$, coefficient of variation. 
The effect of shoots on runoff $\left(R R_{s}\right)$ and sediment $\left(R S_{s}\right)$ reductions was thus determined by subtracting the effect of roots from the total effect of plants. The relative contributions of shoots and roots on runoff and sediment reductions were their respective percentages in the effect of the total plants.

Analysis of variance (ANOVA) was used to detect the treatment effects on measured variables. If significant treatment effects were revealed $(P<0.05)$, the least significant difference (LSD) was used to test comparisons among the treatment means. A paired $t$-test was performed to analyze the differences in variable means before and after cutting the above-ground parts of $A$. capillaris.

Path analysis is a statistical method that decomposes the correlation coefficient $\left(r_{\mathrm{jy}}\right)$ of an independent variable $\left(x_{\mathrm{j}}\right)$-dependent variable $(y)$ into the direct effect of $x_{\mathrm{j}}$ on $y$ (direct path coefficient, $b_{\mathrm{j}}^{*}$ ) and the indirect effect of $x_{\mathrm{j}}$ on $y$ via other variables $x_{\mathrm{k}}$ (indirect path coefficient, $\left.r_{\mathrm{jk}} b_{\mathrm{k}}{ }^{*}\right)$, i.e. $r_{\mathrm{jy}}=b_{\mathrm{j}}{ }^{*}+r_{\mathrm{jk}} b_{\mathrm{k}}{ }^{*}$. The essence is conducting reason analysis from various aspects, through which we can select the optimal path in complex correlation networks.

In this study, vegetation parameters, namely, SH $\left(x_{1}\right)$, SN $\left(x_{2}\right)$, SD (shoot density, $x_{3}$ ), RWD $\left(x_{4}\right)$, Dia. $\left(x_{5}\right)$, RSAD $\left(x_{6}\right)$, RLD $\left(x_{7}\right)$, and RAR $\left(x_{8}\right)$ are independent variables, and runoff rate $\left(y_{1}\right)$ and sediment rate $\left(y_{2}\right)$ are dependent variables.

These statistical analyses were performed with SPSS version 13.0.

\section{Results}

\subsection{Runoff and sediment}

For the intact plant plots, patchy A. capillaris had a significant effect $(P<0.05)$ on runoff and sediment control. Compared to the $\mathrm{C}_{0}$, runoff rates in the other three plant plots ranged from 0.98 to $1.15 \mathrm{~mm} / \mathrm{min}$, with a reduction of approximately $12 \%-25 \%$; meanwhile, sediment rates varied from 0.45 to 2.46 $\mathrm{g} /\left(\mathrm{m}^{2} \cdot \mathrm{min}\right.$ ), with a decrease of up to $58 \%-92 \%$ (Table 2 ), indicating A. capillaris had a stronger effect on reducing sediment than runoff. BP had the lowest values for runoff rate, sediment rate, and sediment concentration $\left(0.98 \mathrm{~mm} / \mathrm{min}, 0.45 \mathrm{~g} /\left(\mathrm{m}^{2} \cdot \mathrm{min}\right)\right.$, and $0.46 \mathrm{~kg} / \mathrm{m}^{3}$, respectively), and thus had the highest values for reductions in these three variables $(25.2 \%$, $92.4 \%$, and $89.9 \%$, respectively). However, corresponding values for LP ranked only second to $\mathrm{C}_{0}$. No significant differences in sediment concentration and sediment rate were detected between treatment $\mathrm{CP}$ and BP. These results suggested that, under our experimental conditions, $\mathrm{CP}$ and $\mathrm{BP}$ are more effective than LP in conserving soil and water.

Table 2 also showed that runoff and sediment significantly increased after clipping off the above-ground parts of A. capillaris. Runoff and sediment rates in root plots were $1.19-1.28 \mathrm{~mm} / \mathrm{min}$ and $2.10-3.76$ $\mathrm{g} /\left(\mathrm{m}^{2} \cdot \mathrm{min}\right)$, respectively, with average increments of $15 \%$ and 2.3 times compared with that in plant plots. Compared with the bare plot, A. capillaris roots reduced runoff and sediment rates by about $2 \%-9 \%$ and $36 \%-64 \%$, respectively, which were lower than the rates produced by intact plants. Similar to the intact plant experiments, CP-root and BP-root performed more effectively than LP-root in reducing runoff and sediment yield.

Analyses of the relative contributions of A. capillaris roots and shoots to runoff and sediment reductions for the three vegetation patterns (CP, BP, and LP) showed that $A$. capillaris shoots contributed greatly to the runoff reduction, accounting for nearly $57 \%-81 \%$.

Table 2 Runoff and sediment yield under different vegetation patterns for intact plant and root plots and reductions in these parameters compared with control plot

\begin{tabular}{ccccccc}
\hline Disposal & $\begin{array}{c}\text { Runoff rate } \\
(\mathrm{mm} / \mathrm{min})\end{array}$ & $\begin{array}{c}\text { Sediment rate } \\
\left(\mathrm{g} /\left(\mathrm{m}^{2} \cdot \mathrm{min}\right)\right)\end{array}$ & $\begin{array}{c}\text { Sediment concentration } \\
\left(\mathrm{kg} / \mathrm{m}^{3}\right)\end{array}$ & Runoff rate & Sediment rate & Sediment concentration \\
\cline { 5 - 7 } & $1.31^{\mathrm{a}}$ & $5.93^{\mathrm{a}}$ & $4.53^{\mathrm{a}}$ & - & - & - \\
C 0 & $1.08^{\mathrm{d}}$ & $1.00^{\mathrm{d}}$ & $0.92^{\mathrm{d}}$ & 17.6 & 83.1 & 79.6 \\
CP-plant & $0.98^{\mathrm{e}}$ & $0.45^{\mathrm{d}}$ & $0.46^{\mathrm{d}}$ & 25.2 & 92.4 & 89.8 \\
BP-plant & $1.15^{\mathrm{c}}$ & $2.46^{\mathrm{c}}$ & $2.13^{\mathrm{c}}$ & 12.2 & 58.5 & 52.7 \\
LP-plant & $1.21^{\mathrm{b}}$ & $3.65^{\mathrm{b}}$ & $3.01^{\mathrm{b}}$ & 7.6 & 38.4 & 33.6 \\
CP-root & $1.19^{\mathrm{bc}}$ & $2.10^{\mathrm{c}}$ & $1.76^{\mathrm{c}}$ & 9.2 & 64.6 & 61.1 \\
BP-root & $1.28^{\mathrm{a}}$ & $3.76^{\mathrm{b}}$ & $2.93^{\mathrm{b}}$ & 2.3 & 36.6 & 35.2 \\
LP-root &
\end{tabular}

Note: Means followed by the same letter within the same column are not significantly different at $P=0.05$ level using the least significant difference (LSD) method. 
On the contrary, the A. capillaris roots made a relatively greater contribution to the sediment reduction, except for the treatment $\mathrm{CP}$ in which the root effect only occupied $46 \%$. The root effects of BP and LP on sediment reduction were $70 \%$ and $62 \%$, respectively.

Overall, greater shoots/ground cover and roots in vegetation patches reduced runoff and soil loss. On one hand, shoots and ground cover are responsible for rainfall interception and the decrease of raindrop impact energy, while ground cover promotes rainfall infiltration into the soil, in turn reducing overland flow velocities and hydraulic shear stresses, thus diminishing the soil erosion potential (Erpul et al., 2002; Regüés and Torri, 2002; Vásquez-Méndez et al., 2010). These are indicative of the importance of canopy cover in regulating runoff processes, as observed by other authors in similar conditions (Wainwright et al., 2002; Bautista et al., 2007). On the other hand, during our experiment period, A. capillaris was at the late growth stage, so its root growth and development had peaked, and its root diameter was thicker than that in the initial growth stage. The root system had formed with a much higher below-ground biomass as well (Table 1). Soil resistance to erosion was thus strengthened and sediment yield would not increase too much when the above-ground parts were removed. In addition, root exudates can cement soil and form a stable aggregate structure, and then strengthen soil cohesion (Martens, 2002). These are closely related to soil erodibility, thus leading to greater root contributions to soil erosion control.

\subsection{Relations between runoff rate and vegetation parameters}

Stepwise regression (Entered $P=0.05$, Rejected $P=0.10)$ showed that only SH $\left(x_{1}\right), \mathrm{SN}\left(x_{2}\right)$, and RLD $\left(x_{7}\right)$ entered the regression equation:

$$
\begin{aligned}
y_{1}=2.600-0.013 x_{1}-0.004 x_{2}-0.035 x_{7}, & \\
& \left(R^{2}=0.948, P=0.000\right) .
\end{aligned}
$$

Equation 5 indicated that $\mathrm{SH}\left(x_{1}\right), \mathrm{SN}\left(x_{2}\right)$, and RLD $\left(x_{7}\right)$ were the main vegetation indices influencing runoff rate in this study, and their direct effects (direct path coefficient, $b_{1}{ }^{*}$ ) were $-0.392,-0.439$, and -0.446 , respectively, with all reaching the extremely significant levels (Table 3).

As observed in Table 4, the three variables (SH, SN and RLD) had inverse effects on runoff rates, indicating an increase in runoff for vegetation patches with lower SH, SN, and RLD. Furthermore, RLD had the greatest total indirect effect on runoff rate, followed by $\mathrm{SN}$ and $\mathrm{SH}$, respectively. Both total effects of vegetation parameters on runoff rate and decision coefficients presented the same order of $\mathrm{RLD}>\mathrm{SN}>\mathrm{SH}$, implying that RLD could be regarded as the determinant for conserving runoff. Though the direct effect of SN $\left(x_{2}\right)$ on runoff rate $\left(y_{1}\right)$ was not the strongest $(-0.439)$ among the three variables, its indirect effect on runoff rate $\left(y_{1}\right)$ via RLD $\left(x_{7}\right)$ was the greatest $(-0.192)$. The indirect effect of RLD $\left(x_{7}\right)$ on runoff rate $\left(y_{1}\right)$ via $\mathrm{SN}\left(x_{2}\right)$ was also relatively higher $(-0.181)$. Hence, properly increasing planting density has practical significance in conserving soil and water, as is consistent with the results of Gyssels et al. (2007). The path and decision coefficients of residue factor $(\varepsilon)$ were 0.228 and 0.052 , respectively, indicating that other factors (rainfall, soil, measurement error, etc.) might also influence the runoff rate.

\subsection{Relations between sediment rate and vegeta- tion parameters}

Stepwise regression was again performed between the sediment rate $\left(y_{2}\right)$ and the eight above-mentioned vegetation variables. The result showed that partial regression coefficients of SH $\left(x_{1}\right)$ and Dia. $\left(x_{5}\right)$ were not significant, while those of SN $\left(x_{2}\right)$ and SD $\left(x_{3}\right)$ approached significant level, and those of other variables were all significant.

As observed in Table 5, the effects of SD $\left(x_{3}\right)$ and Dia. $\left(x_{5}\right)$ on sediment rate $\left(y_{2}\right)$ were not as important as other variables, but $\mathrm{SD}\left(x_{3}\right)$ showed positive effect on sediment rate $\left(y_{2}\right)$. However, from the point of the erosion-reducing potential of vegetation, SD should be important because above-ground biomass increases may result from increasing vegetation cover, thus leading to erosion reduction. Its correlation coefficient

\begin{tabular}{|c|c|c|c|c|c|}
\hline \multirow{2}{*}{ Model } & \multicolumn{2}{|c|}{$\begin{array}{l}\text { Unstandardized } \\
\text { regression }\end{array}$} & \multirow{2}{*}{$\begin{array}{c}\begin{array}{c}\text { Standardized } \\
\text { regression }\end{array} \\
\text { Beta }\end{array}$} & \multirow{2}{*}{$t$} & \multirow{2}{*}{$P$} \\
\hline & B & $\begin{array}{c}\text { Standard } \\
\text { error }\end{array}$ & & & \\
\hline Constant & 2.600 & 0.222 & & 11.724 & 0.000 \\
\hline $\mathrm{SH}\left(x_{1}\right)$ & -0.013 & 0.003 & -0.392 & -4.486 & 0.002 \\
\hline $\mathrm{SN}\left(x_{2}\right)$ & -0.004 & 0.001 & -0.439 & -4.926 & 0.001 \\
\hline $\operatorname{RLD}\left(x_{7}\right)$ & -0.035 & 0.007 & -0.466 & -5.004 & 0.001 \\
\hline
\end{tabular}

Table 3 Coefficients of the regression analysis ${ }^{a}$

Note: ${ }^{\mathrm{a}}$ Dependent variable: runoff rate. $\mathrm{B}$ is unstandardized regression coefficient, and Beta is standardized regression coefficient. 
Table 4 Path analysis of vegetation impacts on runoff rates

\begin{tabular}{|c|c|c|c|c|c|c|}
\hline Path & $\begin{array}{l}\text { Direct effect of } x_{\mathrm{j}} \\
\quad \text { on } y_{1}\left(b_{\mathrm{j}}\right)\end{array}$ & \multicolumn{2}{|c|}{ Indirect effect of $x_{\mathrm{j}}$ on $y_{1}$ via $x_{\mathrm{k}}\left(r_{\mathrm{jk}} b_{\mathrm{k}}^{*}\right)$} & $\begin{array}{l}\text { Total indirect } \\
\text { effect }\left(r_{\mathrm{jk}} b_{\mathrm{k}}{ }^{*}\right)\end{array}$ & $\begin{array}{l}\text { Total effect of } x_{\mathrm{j}} \\
\quad \text { on } y_{1}\left(r_{\mathrm{jy}}\right)\end{array}$ & $\begin{array}{l}\text { Decision coeffi- } \\
\quad \text { cient }(R(j))\end{array}$ \\
\hline$x_{1}$ to $y_{1}$ & -0.392 & $\begin{array}{l}x_{1} \leftarrow \rightarrow x_{2} \rightarrow y_{1} \\
x_{1} \hookleftarrow \longrightarrow x_{7} \rightarrow y_{1}\end{array}$ & $\begin{array}{l}-0.102 \\
-0.173\end{array}$ & -0.275 & -0.667 & 0.370 \\
\hline$x_{2}$ to $y_{1}$ & -0.439 & $\begin{array}{l}x_{2} \hookleftarrow \longrightarrow x_{1} \rightarrow y_{1} \\
x_{2} \hookleftarrow \longrightarrow x_{7} \rightarrow y_{1}\end{array}$ & $\begin{array}{l}-0.091 \\
-0.192\end{array}$ & -0.283 & -0.722 & 0.442 \\
\hline$x_{7}$ to $y_{1}$ & -0.466 & $\begin{array}{l}x_{7} \hookleftarrow \longrightarrow x_{1} \rightarrow y_{1} \\
x_{7} \leftarrow x_{2} \rightarrow y_{1}\end{array}$ & $\begin{array}{l}-0.145 \\
-0.181\end{array}$ & -0.326 & -0.792 & 0.520 \\
\hline$\varepsilon$ to $y_{1}$ & 0.228 & & & & 0.228 & 0.052 \\
\hline
\end{tabular}

Note: $x_{1}, \mathrm{SH} ; x_{2}, \mathrm{SN} ; x_{7}, \mathrm{RLD} ; y_{1}$, runoff rate; $\varepsilon$, residue factor.

Table 5 Pearson correlation coefficients of the vegetation parameters and sediment rates

\begin{tabular}{|c|c|c|c|c|c|c|c|c|c|}
\hline & $x_{1}$ & $x_{2}$ & $x_{3}$ & $x_{4}$ & $x_{5}$ & $x_{6}$ & $x_{7}$ & $x_{8}$ & $y_{2}$ \\
\hline$x_{1}$ & 1.000 & 0.233 & -0.127 & 0.301 & -0.011 & 0.318 & 0.371 & 0.375 & -0.420 \\
\hline$x_{2}$ & & 1.000 & $0.509^{*}$ & 0.301 & -0.248 & 0.303 & 0.412 & 0.335 & -0.308 \\
\hline$x_{3}$ & & & 1.000 & -0.085 & 0.196 & -0.168 & -0.065 & -0.032 & 0.128 \\
\hline$x_{4}$ & & & & 1.000 & 0.050 & $0.883^{* *}$ & $0.938^{* *}$ & $0.947^{* *}$ & $-0.864^{* *}$ \\
\hline$x_{5}$ & & & & & 1.000 & -0.082 & -0.166 & 0.184 & -0.124 \\
\hline$x_{6}$ & & & & & & 1.000 & $0.813^{* *}$ & $0.773^{* *}$ & $-0.877^{* *}$ \\
\hline$x_{7}$ & & & & & & & 1.000 & $0.936^{* *}$ & $-0.817^{* *}$ \\
\hline$x_{8}$ & & & & & & & & 1.000 & $-0.868^{* *}$ \\
\hline$y_{2}$ & & & & & & & & & 1.000 \\
\hline
\end{tabular}

Note: ${ }^{*}$ and ${ }^{* *}$ mean correlation significance at the 0.05 level and 0.01 level, respectively. $x_{1}, \mathrm{SH} ; x_{2}, \mathrm{SN} ; x_{3}, \mathrm{SD} ; x_{4}, \mathrm{RWD} ; x_{5}, \mathrm{Dia}$; $x_{6}$, RSAD; $x_{7}, \mathrm{RLD} ; x_{8}$, RAR; $y_{2}$, sediment rate.

to the erosion rate was low and positive, as could be attributed to its possible correlation to the other parameters that need to be thoroughly analyzed. As can be seen in Table 6, the direct effect of SD $\left(x_{3}\right)$ on sediment rate $\left(y_{2}\right)$ was negative $(-0.774)$ and approached a significant level. Nevertheless, SD $\left(x_{3}\right)$ had a significant positive relation with $\mathrm{SN}\left(x_{2}\right)(0.509$; Table 5). The positive effects of SD $\left(x_{3}\right)$ on sediment rate $\left(y_{2}\right)$ via SN $\left(x_{2}\right)$, Dia. $\left(x_{5}\right)$, and RAR $\left(x_{8}\right)$ could not offset the restriction of RLD $\left(x_{7}\right)(-0.591)$, consequently causing a lower total effect on sediment rate $\left(y_{2}\right)(0.128)$.

Path analysis (Table 6) showed that the direct effects of the eight vegetation parameters on sediment rate $\left(y_{2}\right)$ were in the order of $b_{7}{ }^{*}>b_{5}{ }^{*}>b_{2}{ }^{*}>b_{4}{ }^{*}>b_{1}{ }^{*}>$ $b_{3}{ }^{*}>b_{6}{ }^{*}>b_{8}{ }^{*}$. RSAD $\left(x_{6}\right)$ had a maximal positive decision coefficient (0.711) and both its direct and total effects on sediment rate $\left(y_{2}\right)$ were significantly negative, which can be considered as the primary decision variable. Though the decision coefficient of $\mathrm{SH}\left(x_{1}\right)$ ranked only the second to $\operatorname{RSAD}\left(x_{6}\right)$, its direct effect on sediment rate $\left(y_{2}\right)$ was not significant. The decision coefficient of RWD $\left(x_{4}\right)$ ranked the third. Besides, RWD $\left(x_{4}\right)$ had a higher direct effect and an extremely significant comprehensive effect on sediment rate $\left(y_{2}\right)$, and its indirect effect on sediment rate $\left(y_{2}\right)$ via RSAD $\left(x_{6}\right)$ also contributed to the reduction of soil loss. According to the above-mentioned analyses, both RSAD and RWD were the main vegetation indicators responsible for erosion control under our study conditions.

Similarly, the path and decision coefficients of $\varepsilon$ were 0.161 and 0.026 , respectively, implying that other factors (rainfall, underlying surface, measurement error, etc.) might also influence the sediment rate.

\section{Discussion and conclusions}

Our research confirms the importance of spatial discontinuities induced by patterned vegetation in hillslope runoff processes, showing that patched A. capillaris could conserve runoff and soil, and of the patterns employed in our tests, BP and CP performed more effectively than LP on erosion control. Actually, in areas with a patchy distribution of vegetation, the 
Table 6 Path analysis of vegetation impacts on sediment rates

\begin{tabular}{|c|c|c|c|c|c|c|c|c|c|c|c|}
\hline \multirow{2}{*}{ Factor } & \multirow{2}{*}{$\begin{array}{c}\text { Direct } \\
\text { effect of } x_{\mathrm{j}} \\
\text { on } y_{2}\left(b_{\mathrm{j}}^{*}\right)\end{array}$} & \multicolumn{8}{|c|}{ Indirect effect of $x_{\mathrm{j}}$ on $y_{2}$ via $x_{\mathrm{k}}\left(r_{\mathrm{jk}} b_{\mathrm{k}}^{*}\right)$} & \multirow{2}{*}{$\begin{array}{c}\text { Total effect of } \\
x_{\mathrm{j}} \text { on } y_{2}\left(r_{\mathrm{jy}}\right)\end{array}$} & \multirow{2}{*}{$\begin{array}{c}\text { Decision } \\
\text { coefficient } \\
(R(j))\end{array}$} \\
\hline & & $\rightarrow x_{1}$ & $\rightarrow x_{2}$ & $\rightarrow x_{3}$ & $\rightarrow x_{4}$ & $\rightarrow x_{5}$ & $\rightarrow x_{6}$ & $\rightarrow x_{7}$ & $\rightarrow x_{8}$ & & \\
\hline$x_{1}$ & -0.144 & & 0.158 & 0.099 & 0.094 & -0.036 & -0.355 & 3.358 & -3.594 & -0.420 & 0.100 \\
\hline$x_{2}$ & 0.678 & -0.034 & & -0.394 & 0.094 & -0.832 & -0.339 & 3.731 & -3.213 & -0.308 & -0.878 \\
\hline$x_{3}$ & -0.774 & 0.018 & 0.345 & & -0.027 & 0.659 & 0.188 & -0.591 & 0.309 & 0.128 & -0.797 \\
\hline$x_{4}$ & 0.312 & -0.043 & 0.208 & 0.066 & & 0.168 & -0.987 & 8.493 & -9.080 & -0.864 & -0.639 \\
\hline$x_{5}$ & 3.356 & 0.002 & -0.168 & -0.152 & 0.016 & & 0.091 & -1.504 & -1.764 & -0.124 & -12.090 \\
\hline$x_{6}$ & -1.118 & -0.046 & 0.205 & 0.130 & 0.275 & -0.274 & & 7.360 & -7.410 & -0.877 & 0.711 \\
\hline$x_{7}$ & 9.056 & -0.053 & 0.279 & 0.051 & 0.293 & -0.557 & -0.909 & & -8.976 & -0.817 & -96.812 \\
\hline$x_{8}$ & -9.591 & -0.054 & 0.227 & 0.025 & 0.295 & 0.617 & -0.864 & 8.476 & & -0.868 & -75.325 \\
\hline$\varepsilon$ & 0.161 & & & & & & & & & 0.161 & 0.026 \\
\hline
\end{tabular}

relationships between runoff-erosion rates and vegetation covers are even more pronounced, and there are different hydrological and erosional responses to different patterning surfaces (Cerdà, 1997). Besides, runoff and soil loss or soil properties in natural environments have been found to be different between bare and vegetated patches (Lesschen et al., 2008; Vásquez-Méndez et al., 2010). Runoff patterns are closely linked to the vegetation patterns in some Mediterranean environments (Cerdà, 1995). However, this study only investigated the runoff and sediment discharge. The interaction between vegetated and bare areas on runoff and sediment is not clear yet, and can be one aspect for the follow-up researches to target.

Numerous studies have explored the relations between soil erosion and vegetation indicators, and different functional relationships were obtained, such as exponential (Mamo and Bubenzer, 2001a, b; Gyssels and Poesen, 2003), Hill model (De Baets et al., 2006), and linear (Zhou and Shangguan, 2007). Zhou and Shangguan (2005) also found that the reinforcement of soil anti-scouribility can be fitted well logarithmically by RSAD. Whatever the function's form, the final purpose is to reveal the control effect of vegetation on runoff and sediment. Based on this, the present study analyzed each vegetation parameter that influenced runoff and sediment yield using the path analysis method. The results found that RLD and SN were key parameters influencing runoff rate, while RSAD and RWD were central indicators affecting sediment rate. This finding accorded with practical specialty, as can be a first step toward field and targeted practices at a large spatial scale, such as a watershed or a region.
Soil erosion is a very complex process that is influenced by many factors, most of which have seasonal cycles. This study used an artificial soil and vegetation cover to measure the effects of vegetation patterns on runoff and soil loss. In the field, many relevant soil properties vary with the variety of spatial patterns of plants and contribute to the way that vegetation patterns affect runoff and soil loss. The soil used in this experiment was largely homogeneous as it consisted of well-mixed topsoil, and the plants had been growing in the soil for only one year. By ignoring the soil properties that covary with plant patterns, the experimental situation differed in significant ways from field situations. However, such variance is always going to be difficult to avoid in an experiment like this one. The experimental design in this study was restricted in terms of slope angle $\left(15^{\circ}\right)$, rainfall intensity $(90 \mathrm{~mm} / \mathrm{h})$, plant species (A. capillaris), plant size (uniform age), and plot length $(2 \mathrm{~m})$, yet the findings can offer basic data for understanding erosion processes and vegetation construction aiming at soil and water conservation, and provide an insight for conducting deep studies, such as a more strategic variety of treatments (e.g. multiple slope angles, one vegetation pattern with different-size gaps or planting densities, or fundamental hydrological processes).

\section{Acknowledgments}

This work was funded by the National Natural Science Foundation of China (41301298), the State Key Program of National Natural Science Foundation of China (41030532), and the Special Fund of Strategic Priority Research Program of Chinese Academy of Sciences (XDA05060300). 


\section{References}

Aguiar M R, Sala O E. 1999. Patch structure, dynamics and implications for the functioning of arid ecosystems. Trends in Ecology \& Evolution, 14: 273-277.

Bautista S, Mayor A G, Bourakhouadar J, et al. 2007. Plant spatial pattern predicts hillslope runoff and erosion in a semiarid Mediterranean landscape. Ecosystems, 10: 987-998.

Beard J S. 1967. A study of patterns in some Western Australian heath and mallee communities. Australian Journal of Botany, 15: 131-139.

Bedford D R, Small E E. 2008. Spatial patterns of ecohydrologic properties on a hillslope-alluvial fan transect, central New Mexico. Catena, 73: 34-48.

Bernstein L, Bosch P, Canziani O, et al. 2008. Climate Change 2007: Synthesis Report: An Assessment of the Intergovernmental Panel on Climate Change. Geneva: IPCC.

Boer M, Puigdefábregas J. 2005. Effects of spatially structured vegetation patterns on hill-slope erosion in a semiarid Mediterranean environment: a simulation study. Earth Surface Processes and Landforms, 30: 149-167.

Braud I, Vich A I J, Zuluaga J, et al. 2001. Vegetation influence on runoff and sediment yield in the Andes region: observation and modeling. Journal of Hydrology, 254: 124-144.

Cerdà A. 1995. Factores y Variaciones Espacio-Temporales de la Infiltración en los Ecosistemas Mediterráneos. Logroño: Editorial Geoforma, 159.

Cerdà A. 1997. The effect of patchy distribution of Stipa tenacissima L. on runoff and erosion. Journal of Arid Environments, 36: 37-51.

Chen H S, Shao M A, Li Y Y. 2008. Soil desiccation in the Loess Plateau of China. Geoderma, 143: 91-100.

De Baets S, Poesen J, Gyssels G, et al. 2006. Effects of grass roots on the erodibility of topsoils during concentrated flow. Geomorphology, 76 : 54-67.

Dekker S C, Rietkerk M, Bierkens M F P. 2007. Coupling microscale vegetation-soil water and macroscale vegetation-precipitation feedbacks in semiarid ecosystems. Global Change Biology, 13: 671-678.

D'Odorico P, Porporato A. 2006. Ecohydrology of arid and semiarid ecosystems: an introduction. In: D’Odorico P, Porporato A. Dryland Ecohydrology. Netherlands: Springer, 1-10.

Erpul G, Norton L D, Gabriels D. 2002. The effect of wind on raindrop impact and rainsplash detachment. Transactions of the ASAE, 46: $51-62$.

Fowler N. 1986. The role of competition in plant communities in arid and semiarid regions. Annual Review of Ecology and Systematics, 17: 89-110.

Greenwood J E G W.1957. The development of vegetation patterns in Somaliland Protectorate. The Geographical Journal, 123: 465-473.

Guo Z S. 2000. Effective, critical and potential coverage of vegetation community for soil and water conservation. Bulletin of Soil and Water Conservation, 20(2): 60-62.

Gyssels G, Poesen J. 2003. The importance of plant root characteristics in controlling concentrated flow erosion rates. Earth Surface Processes and Landforms, 28: 371-384.

Gyssels G, Poesen J, Knapen A, et al. 2007. Effects of double drilling of small grains on soil erosion by concentrated flow and crop yield. Soil and Tillage Research, 93: 379-390.
Lesschen J P, Cammeraat L H, Kooijman A M, et al. 2008. Development of spatial heterogeneity in vegetation and soil properties after land abandonment in semi-arid ecosystems. Journal of Arid Environments, 72: 2082-2092.

Li F M, Xu J Z, Sun G Z. 2003. Restoration of degraded ecosystems and development of water-harvesting ecological agriculture in the semi-arid Loess Plateau of China. Acta Ecologica Sinica, 23: 1901-1915.

Mamo M, Bubenzer G D. 2001a. Detachment rate, soil erodibility and soil strength as influenced by plant roots: Part I. Laboratory study. Transactions of the ASAE, 44: 1167-1174.

Mamo M, Bubenzer G D. 2001b. Detachment rate, soil erodibility and soil strength as influenced by plant roots: Part II. Field study. Transactions of the ASAE, 44: 1175-1181.

Martens D A. 2002. Relationship between plant phenolic acids released during soil mineralization and aggregate stabilization. Soil Science Society of America Journal, 66: 1857-1867.

Nobel S P. 1990. Physicochemical and Environmental Plant Physiology ( $2^{\text {rd }}$ edition). Burlington: Elsevier Academic Press.

Pan C Z, Shangguan Z P. 2006. Runoff hydraulic characteristics and sediment generation in sloped grassplots under simulated rainfall conditions. Journal of Hydrology, 331: 178-185.

Pan C Z, Shangguan Z P, Lei T W. 2006. Influence of grass and moss on runoff and sediment yield on sloped loess surface under simulated rainfall. Hydrological Processes, 20: 3815-3824.

Puigdefábregas J. 2005. The role of vegetation patterns in structuring runoff and sediment fluxes in drylands. Earth Surface Processes and Landforms, 30: 133-147.

Rango A, Tartowski S L, Laliberte A, et al. 2006. Islands of hydrologically enhanced biotic productivity in natural and managed arid ecosystems. Journal of Arid Environments, 65: 235-252.

Regües D, Torri D. 2002. Rainfall kinematics energy effect on physical properties dynamics and crusting of a clayey bare soil. Cuaternarioy Geomorfología, 16: 57-71.

Shi H, Shao M A. 2000. Soil and water loss from the Loess Plateau in China. Journal of Arid Environments, 45: 9-20.

Tang K L. 2004. Soil and Water Conservation in China. Beijing: Science Press, 885.

Vásquez-Méndez R, Ventura-Ramos E, Oleschko K, et al. 2010. Soil erosion and runoff in different vegetation patches from semiarid Central Mexico. Catena, 80: 162-169.

Vásquez-Méndez R, Ventura-Ramos E, Oleschko K, et al. 2011. Soil erosion processes in semiarid areas: the importance of native vegetation. In: Danilo G. Soil Erosion Studies. Shanghai: InTech.

Wainwright J, Parsons A J, Schlesinger W H, et al. 2002. Hydrology-vegetation interactions in areas of discontinuous flow on a semi-arid bajada, Southern New Mexico. Journal of Arid Environments, 51: 319-338.

Wei W, Chen L D, Fu B J, et al. 2007. The effect of land uses and rainfall regimes on runoff and soil erosion in the semi-arid loess hilly area, China. Journal of Hydrology, 335: 247-258.

Worrall G A. 1959. The Butana grass patterns. Journal of Soil Science, 10: $34-53$.

Zhou Z C, Shangguan Z P. 2005. Soil anti-scouribility enhanced by plant roots. Journal of Integrative Plant Biology, 47: 676-682.

Zhou Z C, Shangguan Z P. 2007. The effects of ryegrass roots and shoots on loess erosion under simulated rainfall. Catena, 70: 350-355. 